\title{
Mathematical Indices for Comparing Small Fruit Crops for Harvest Time and Trait Similarity
}

\author{
Shahrokh Khanizadeh ${ }^{1}$ \\ 430 Boul. Gouin, Agriculture Canada, Research Station, St-Jean-sur- \\ Richelieu, Que. J3B 3E6 Canada
}

\section{Mamdouh A. Fanous ${ }^{2}$ \\ 21111 Lakeshore Rd., Macdonald College of McGill University, Ste- Anne-de-Bellevue, Que. H9X 1C0 Canada}

\begin{abstract}
Additional index words. breeding, sensory evaluation, genotype evaluation, index of earliness, index of concentrated cropping, index of deviation, phenotypic similarity, computer program
\end{abstract}

\begin{abstract}
Three mathematical indices were developed to estimate: 1) potential for early dollar return or early ripening (IE), 2) concentrated cropping (IC), and 3) deviation or similarity of a genotype to known cultivars (ID). Early ripening genotypes with high yield early in the season will have larger IE values than late genotypes with lower yield early in the season. Genotypes with few harvests will have larger IC values than those requiring several harvests. The ID index helps to identify and group genotypes with similar characteristics. These indices condense numerous values or arrays of traits into single index values, thereby simplifying genotype comparisons.
\end{abstract}

Early ripening, concentrated cropping, and similarity to known genotypes are important to strawberry (Fragaria $\times$ ananassa Duch.) breeders and other researchers engaged in the evaluation of small fruit crops. Estimation of the earliness of a new genotype in comparison with other known genotypes is usually done by comparative visual scoring or by comparing the cumulative percentage of ripe fruit after several harvests (Ballington et al., 1990; Khanizadeh et al. 1990; Moore and Clark, 1989a, 1989b). The conventional percentage of ripe fruit per harvest does not take into account the total yield, a very important factor in marketing small fruit early in the season, nor does it identify genotypes that have potential for early dollar returns. It is possible for a low-yielding genotype with high percentage ripe fruit early in the season to be more profitable, because of higher market price, than high-yielding genotypes with a low percentage of ripe fruit early in the season. Concentration of cropping often is measured by the number of harvests necessary to recover the bulk of the commercial crop. New genotypes also may be assessed by scoring other traits such as appearance, firmness, flavor, vigor, color, susceptibility to diseases, acidity, sweetness, mealiness, etc., by subjective or objective measures (Ballington et al. 1990; Granger et al. 1991; Khanizadeh et al. 1990; Moore and Clark,

\footnotetext{
Received for publication 8 July 1991. Accepted for publication 9 Dec. 1991. Agriculture Canada contribution no. 335/91.10.03R. The cost of publishing this paper was defrayed in part by the payment of page charges. Under postal regulations, this paper therefore must be hereby marked advertisement solely to indicate this fact.

'Research Scientist, Programmer.

${ }^{2}$ Associate Professor of Statistics.
}

1989a, 1989b). However, quantifying the overall phenotypic difference between a new genotype and known cultivars is difficult, especially when many traits are compared. It would be helpful to evaluators to have single indices for comparing genotypes instead of comparing many values for estimating the ripening season, concentration of cropping and deviation, or similarity to other genotypes.

Three mathematical indices were developed to estimate: 1) potential for early dollar return or early ripening (IE), 2) concentrated cropping (IC), and 3) deviation from or similarity of a genotype to known cultivars (ID).

Hypothetical data are used to illustrate the application of these three indices (Table 1). The 10 given genotypes in this example have different degrees of earliness, crop concentration, and fruit or plant score values. The first harvest date occurred on 24 June (day $=1$ ) and fruits were harvested at 5-day intervals up to July 15 (day $=21$ ). Five plant and/or fruit characteristics (S1-S5) were evaluated on a scale of 1 to 5 .

Index of earliness. Equation [1] estimates the potential for early dollar return or early ripening (IE) and considers the yield per harvest relative to the starting harvest date.

$$
\mathrm{IE}=\sum_{\mathrm{i}=1}^{\mathrm{n}}\left(\frac{\mathrm{Y}_{\mathrm{i}}}{\mathrm{D}_{\mathrm{i}}}\right) / \mathrm{n}
$$

where $\mathrm{i}=1,2, \ldots, \mathrm{n}, \mathrm{n}=$ number of harvests; $\mathrm{Y}_{\mathrm{i}}$ is the yield at ith harvest; and $\mathrm{D}_{\mathrm{i}}$ is the number of days from the start of harvesting to ith harvest (e.g., $D_{1}=1$ for first harvest on June $24, D_{2}=6$ for second harvest on 29 June, etc.). Late-ripening genotypes with low percentages of total yield early in the season will have smaller IE val- ues than genotypes with high percentages of yield early in the season (Table 1). For example, genotype 7 with IE $=160$ is a genotype with high potential for early dollar returns, whereas genotype 4 with IE $=11.1$ is a genotype with low potential for early sales (Table 1). The following numerical example illustrates the calculation of the IE for genotype 1, using the hypothetical data from Table 1.

$\mathrm{E}_{\text {Genotype } 1}=$
$\frac{(50 / 1)+(200 / 6)+(300 / 11)+(200 / 16)+(50 / 21)}{5}$

$=25.1$

The advantage of IE over the conventional percent yield per harvest is that it takes yield magnitude per harvest into account. Genotypes 1 and 9 from Table 1 are used to illustrate this point. Using the conventional method, both genotypes have the same percent yield per harvest (Table 1) for ripening season. However, genotype $9(\mathrm{IE}=50.2)$ has a greater potential for early dollar returns than genotype 1 (IE = 25.1) because of higher yield early in the season.

Index of cropping concentration. Equation [2] is used to calculate the index of cropping concentration (IC) for a genotype relative to others in the same trial.

$$
\mathrm{IC}=\frac{\sqrt{\sum_{i=1}^{n}\left(Y_{i}-\bar{Y}\right)^{2} / n}}{n}
$$

$\mathrm{i}=1,2, \ldots, \mathrm{n}, \mathrm{n}=$ number of harvests; $\mathrm{Y}_{\mathrm{i}}$ is the percent yield at the ith harvest; and $\mathrm{Y}$ is the average of percent yield for $\mathrm{n}$ harvests. Genotypes with few harvests (a desirable trait for mechanical harvesting) will have larger IC values than those requiring several harvests (Table 1). Genotypes 7 and 8, for example, had IC values of 8 and were harvested on one date, whereas genotypes 1,2 , 9 , and 10 had the longest harvest periods (IC $=2.4$ ). The indices IE and IC are independent of each other, e.g., genotypes 7 and 8 had identical IC values but different IE values (Table 1).

The following numerical example illustrates the calculation of IC for genotype 1 using the hypothetical data from Table 1.

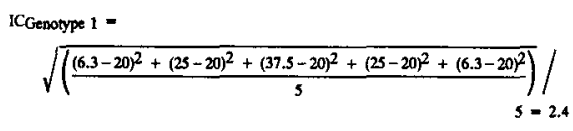

The advantage of IC over the conventional percent yield per harvest is that it condenses a large array of percentages per harvest into a single value, thereby facilitating genotype comparison.

The indices IE and IC are applicable to any horticultural crop with multiple harvests.

Index of deviation or similarity. Breeders and growers often want to know the degree of deviation or similarity of new and commercial cultivars. Comparison of individual characteristics may not give a complete picture. Also, it is easier to have a single index value to compare rather than an array of traits. Equation [3] is used to calculate an index of 


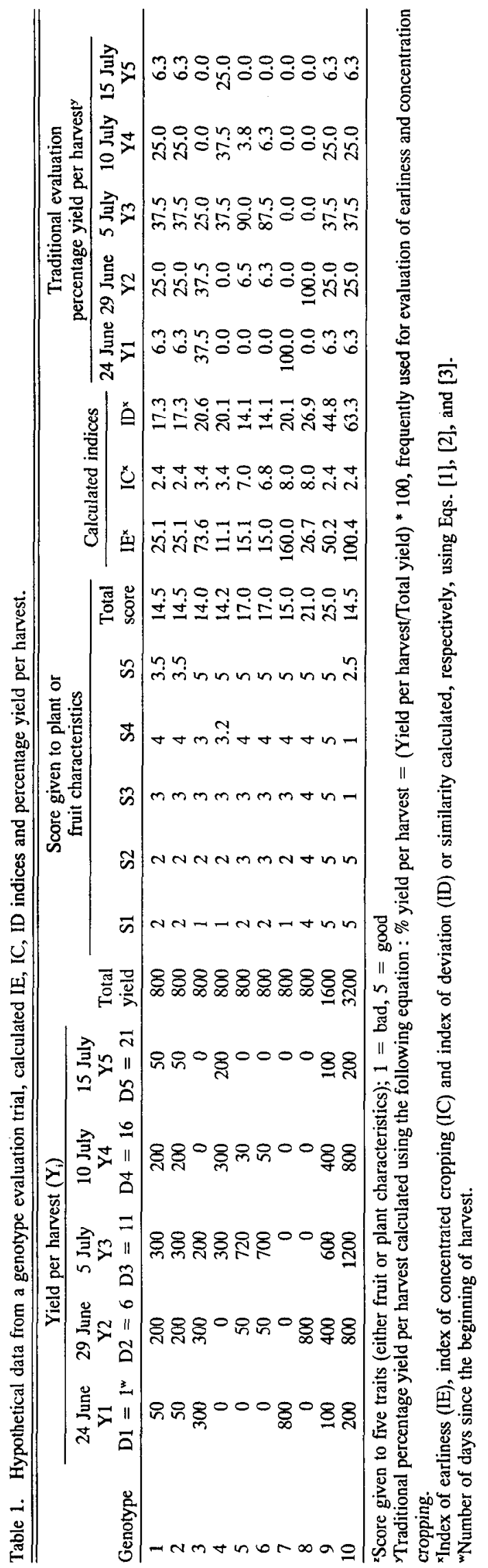

HORTSCIENCE, VOL. 27(4), APRIL 1992 deviation (ID) or similarity between genotypes in the same trial. The index ID considers all the characteristics measured for the genotypes.

$$
\mathrm{ID}_{\mathrm{i}^{\prime}}=\sum_{j=1}^{t}\left[\sum_{\substack{i=1 \\ i \neq i^{\prime}}}^{c}\left(\mathrm{~S}_{\mathrm{i}^{\prime} \mathrm{j}}-\mathrm{S}_{\mathrm{ij}}\right)^{2}\right] / t
$$

where $i^{\prime}=$ specific genotype selected from $c$ total genotypes; $i=$ other genotype in the same trial; $j=1,2, \ldots, t$ for the specific trait of $\mathrm{t}$ total traits for $\mathrm{i}^{\prime}$ th an ith genotype; and $\mathrm{S}$ is the score value given to each $\mathrm{i}^{\prime}$ th and ith genotype for a specific $j$ th trait. Genotypes 1 and 2 and genotypes 5 and 6 were similar in terms of plant and/or fruit characteristics, and each pair had the same ID value, but genotypes 9 and 10 with ID values of 44.8 and 63.3 are markedly different from these (Table 1).

The following numerical example illustrates the calculation of ID for genotype 1 using the hypothetical data from Table 1.

$$
\begin{aligned}
& \mathrm{ID}_{\text {Genotype } 1}=\left\{\left[(2-2)^{2}+(2-1)^{2}+\right.\right. \\
& (2-1)^{2}+(2-2)^{2}+(2-2)^{2}+ \\
& (2-1)^{2}+(2-4)^{2}+(2-5)^{2}+ \\
& \left.(2-5)^{2}\right]+\left[(2-2)^{2}+(2-2)^{2}+(2\right. \\
& -2)^{2}+(2-3)^{2}+(2-3)^{2}+(2-2)^{2} \\
& \left.+(2-4)^{2}+(2-5)^{2}+(2-5)^{2}\right]+ \\
& \cdots \ldots . .\left[(3.5-3.5)^{2}+(3.5-5)^{2}+(3.5\right. \\
& -5)^{2}+(3.5-5)^{2}+(3.5-5)^{2}+(3.5 \\
& -5)^{2}+(3.5-5)^{2}+(3.5-5)^{2}+(3.5 \\
& \left.\left.-2.5)^{2}\right]\right\} / 5=17.3
\end{aligned}
$$

The ID index helps to place genotypes with similar plant and fruit characteristics into one group. It quantifies how different or similar a particular genotype (in terms of score) is compared with others (Granger et al. 1991). ID has other advantages over the conventional additive or weighted score. Genotypes 1 and 10 from Table 1 are used to illustrate this point. Using the additive method, both genotypes have the same total score (Table 1) for plant or fruit characteristics. However, ID yields more information because it takes score variation per trait into account (Table 1). The ID can be used to evaluate any horticultural crop.

The above formulae can be easily incorporated into Statistical Analysis System (SAS, 1988) for genotype evaluation using multiple or paired comparisons. However, for ease of use, these formulae have been incorporated into an expert system named EVAL, designed for a microcomputer. EVAL was developed on an IBM/AT 386 using MS-DOS version 4.0 and GW-BASIC version 2.23, then compiled to machine language with the Microsoft Basic Compiler. After execution, the user is asked to enter the genotype name, yield per harvest, and number of days relative to first harvest day, at which point the program immediately generates IE and IC. A template is also available for calculation of ID using Lotus (1-2-3 Access System, Lotus Development Corp.). The EVAL program and the Lotus spreadsheet template are available upon request from S.K. on a 3.5or 5.25 -inch micro flexible disk at a nominal 
cost (disk, postage, and handling). It can be run on an IBM-PC/XT/AT/PS, or is compatible with $512 \mathrm{~K}$ memory (RAM).

\section{Literature Cited}

Ballington, J. R., C.M. Mainland, S.D. Duke, A.D. Draper, and G.J. Galletta. 1990. 'O'Neal' southern highbush blueberry. HortScience
25(6):711-712.

Granger, R. L., S. Khanizadeh, J. Fortin, K. Lapsley, and M. Meheriuk. 1991. Sensory evaluation of several scab-resistant apple genotypes. Fruit Var. J. (In press.)

Khanizadeh, S., D. Buszard, M. Lareau, and D. Bagnara. 1990. 'Chambly' strawberry. HortScience 25(8):984-985.
Moore, J.M. and J.R. Clark. 1989a. 'Choctaw' blackberry. HortScience 24(5) :862-863.

Moore, J.M. and J.R. Clark. 1989b. 'Navaho' erect thornless blackberry. HortScience 24(5):863-865.

Statistical Analysis System (SAS). 1988. SAS/ STAT, SAS/BASIC guide for personal computers. Version 6.04 (ed.) SAS Inst., Cary, NC. 